\title{
The Connecting Method for the Spiral Blades of Concrete Mixer Truck
}

\author{
Xinhui LIU, Yanhong SONG, Feng REN ${ }^{*}$ Jinshi CHEN, Min ZHAO
}

\begin{abstract}
For the spiral blade of the concrete mixing tank of concrete mixer truck, in order to satisfy the stirring and discharging performance, the installation angle and helix angle of the blade should be assigned according to their segmentation function. Due to the different helix angles and the installation tilt angles, a junction gap of blade is formed at the joint, resulting in the severe silting of discharge or the uneven agitation. We put forward a more reasonable solution by using the MFG (method of fitting gradient) to solve the gap connection of spiral blades. The MFG that can reduce the discharging residual rate of the mixing material has been verified by experiments and applied to actual mass production. We also make the coupling simulation of Multi-Physics Field based on simulation software $17-S T A R C C M+\circledR$ to visually verify the scientificity of design and study the complex stresses distribution inside the actual mixing tank. Finally, we provide an up-to-date reference for the design of spiral logarithmic blade, solving the problem of the gap at the traditional spiral-blade connection.
\end{abstract}

Keywords: experimental validation; junction gap; MFG; multi-physics field coupling; spiral blade

\section{INTRODUCTION}

In recent years, the spiral blade of most pear shaped concrete agitators adopts conical logarithmic-style blade, Archimedes-style blade or two-type combined blade. Many concrete mixing tanks on the market adopt the nonisometric conical logarithmic-style spiral blade, because it has good streamline relative to Archimedes' spiral structure. The concrete inside the mixing tank has good fluidity [1, 2]. The mixing tank usually has three parts, including anterior cone, middle tube and rear cone. The concept of "calculating cone" can be applied to the design calculating of the spiral blade of anterior cone and rear cone, which can date back to the reference [3-5]. In order to meet the performance of stirring and discharging when the mixing tank is working, the spiral angle and the inclination angle of blade should be reasonably arranged. The mutation is produced at the joint of two-blade connection due to different inclination angles and spiral angles at different sections. It causes the failure of the blade connection or the excessive change of the blade connection, as shown in Fig. 1. The mutation makes a serious effect on the performance of mixing and discharging of tank. The function of tank's discharging will drop sharply at the abrupt point when discharging. What is more, the concrete material will be deposited at the connecting abrupt place. In order to change this situation, many manufacturers have adopted the following solutions: Firstly, some manufacturers may use the method of steel forced welding at the junction between two spiral blades. The disadvantage is that the service life of the blade is reduced, because of the existence of welding stress within the strong welding. Secondly, designers usually use three-dimensional modeling code (Pro/E, UG, CATIA, etc.) to fit two blades directly. However, the parameters of fitting blade need to be modified frequently $[5,6]$. Thirdly, some producers use the curved surface like bridge to connect different blades. Actually, this method will cause an oversize angle between the different spiral blades, so the bridging at the cone will be very difficult. The fourth method is the spiral mesh generation for the blade connection, which is mainly applied to the design of similar blade with constant cross-section, shape and size, but it has some limitations [6]. The current schemes are not great, and the performance of design or using of the agitator is reduced to some extent. In order to solve the defects in the connection gap of spiral blades, we present the MFG whose feasibility is verified by physical production and application. Because of the complexity of the internal applied force state of agitator, it is impossible to conduct accurately quantitative research. Recently, there are two major methods to research complex applied force inside agitator. Firstly, it is the numerical flow field analysis by using CFD techniques [7-14], but the multifield coupling is ignored under this condition. Secondly, some researchers use the PIV (Particle Image Velocimetry) technology to study mixing tank. Because the applied forces inside mixing tank are complicated and more working-condition factors are ignored [15], this method cannot accurately reproduce the complex force state of mixing tank. Based on the coupling simulation of MultiPhysics Field, the internal applied force state and the performance of the stirring tank will be quantitatively studied in this paper. We provide an ideal theoretical basis for the blade connection design, and we also present an upto-date way for the precise research of the complex state of the mixing tank.

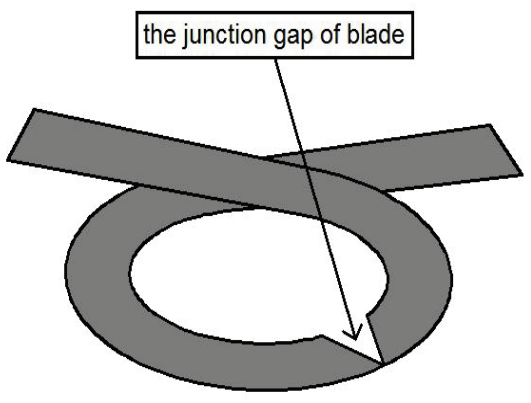

Figure $1 \mathrm{Gap}$ at the joint of the spiral blades

\section{THE CALCULATION OF FITTING BLADE 2.1 Blade Arrangement of Mixing Tank}

For a pear shaped mixing tank with the conical logarithmic spiral blade, arrangement of spiral blade has the following schemes. Firstly, as shown in Fig. 2, the spiral blade of anterior cone is a spirally oblique conical surface with the constant cross-section, the middle spiral blade is a spirally oblique surface with the constant cross section, and the spiral blade of rear cone is a spirally oblique conical surface with the variable cross section. The performance of this tank is better [5], but the parameters calculation in the process of design is more complex. There 
is a gap on the blade at the junction of the middle section and the rear cone. The first blade arrangement is better applied to the tank's design of small capacity. Secondly, as shown in Fig. 3, the spiral blade of anterior cone is a spirally oblique conical surface with the constant cross section, the middle spiral blade is a spirally oblique surface with the constant cross section, and the spiral blade of rear cone is a spirally positive conical surface with the variable cross section. The performance of this blade arrangement is not as good as the first one, but the parameters calculation in the design process is acceptable. The second blade arrangement is more applicable to the tank's design of small or medium capacity. Thirdly, as shown in Fig. 4, the spiral blade of anterior cone is a spirally oblique conical surface with the constant cross section, the middle spiral blade is a spirally positive surface with the constant cross section, and the spiral blade of rear cone is a spirally positive conical surface with the variable cross section. The performance and the workload of design calculation can be accepted. There is a gap on the blade at the junction between the middle and the anterior cone. The third blade arrangement is better applied to the tank design of large capacity. After considering various factors, the MFG can be proposed for the connection design of spiral blade. Meanwhile, the streamline of the spiral blade and the service life of the stirring blade can be taken into account.

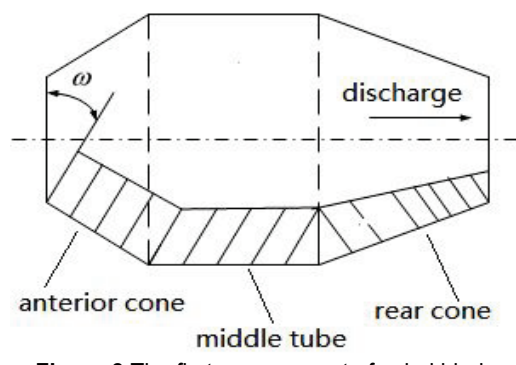

Figure 2 The first arrangement of spiral blade

\subsection{Implementation of the MFG}

As shown in Fig. 3, a gap appears on the blade at the junction of the rear cone spiral blade and the middle spiral blade. We use this blade arrangement as an example to carry on the detailed MFG in order to solve the poor problem of the blade connection. First, we establish the cylindrical coordinates shown in Fig. 5. Second, the cross section is divided into equal segments to calculate conveniently. According to actual calculating situation, the number of equal segments we take is 64 , as shown in Fig. 6.

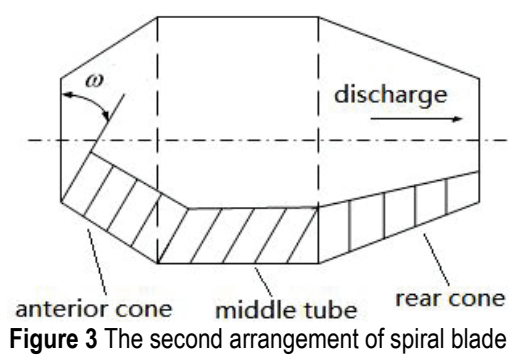

In Fig. 3, the spiral blade of the middle section is a spiral surface with constant cross section. The spiral angle of the spiral blade is an important parameter of the blade. The larger the spiral angle is, the worse the performance of stirring is, the better the performance of the discharging is, and vice versa $[3,5]$

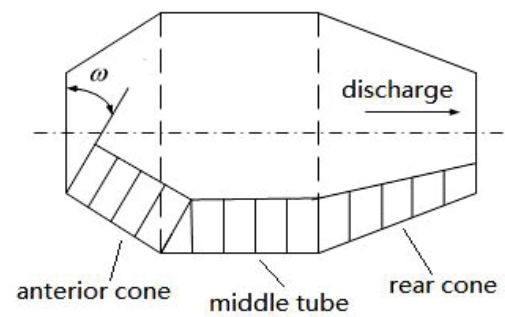

Figure 4 The third arrangement of spiral blade

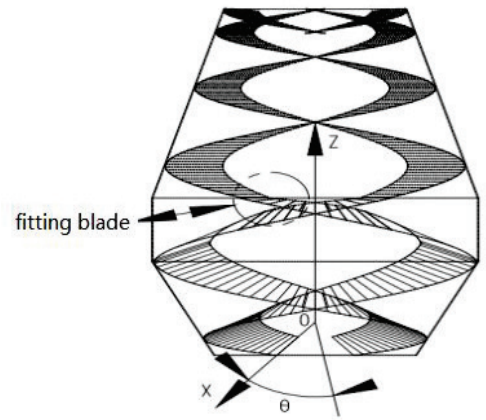

Figure 5 The cylindrical coordinates of calculating

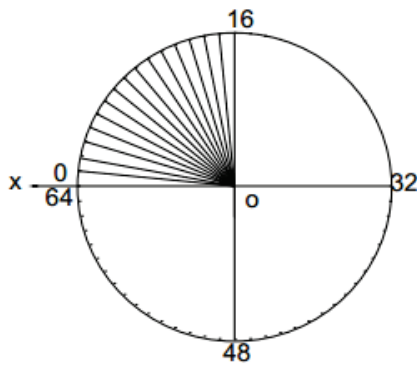

Figure 6 The bisection diagram of design of cross section of mixing tank

If the top helix angle $\left(\beta_{1}\right)$ of the cylindrical helical blade and the root helix angle $\left(\beta_{2}\right)$ of the middle of stirring tank are taken, they satisfy the following relation:

$\frac{\tan \beta_{1}}{R-B}=\frac{\tan \beta_{2}}{R}$,

where, $R$ is the radius of the mixing tank in the middle of the cylinder, $B$ is the blade width.

The root helix angle is taken as equal helix angle, and then:

$\tan \beta_{2}=\frac{2 \pi R}{n_{i} \Delta Z}$

where, $\Delta Z$ is the increment of $Z$ axis in each order; $n_{i}$ is the equal division point on cross section (this paper takes 64).

The point $i$ in the cylindrical segment is

$i=L_{2} / \Delta Z$,

where, $i$ is the number of segments as the $Z$ direction of the spiral blade at the middle tube.

The formula for calculating the vertical coordinate of the spiral curve in the wall of cylinder is 
$Z_{i+1}=Z_{i}+\Delta Z$

where, $Z_{i}$ is the $Z$ direction coordinate of the spiral blade in the cylindrical section, when calculating the root and top coordinates, the relevant geometric parameters can be seen in Fig. 7. In addition, the relevant parameters can be seen in the reference [7, 16-19].

The formula for calculating the vertical coordinate of the root point of the spiral blade at the cylindrical section in the wall of the tank is

$$
M Z_{1}(i)=i \times \Delta Z
$$

The vertical coordinate of the top point of the spiral blade in the cylindrical section is

$$
M Z_{2}(i)=M Z_{1}(i)+B \sin w
$$

The horizontal coordinate of the root point of the spiral blade in the cylindrical section is

$M R_{1}(i)=R$

The horizontal coordinate of the top point of the spiral blade in the cylindrical section is

$$
M R_{2}(i)=R-B \cos w
$$

Since the inclination angle of rear cone is different from that of the front cone and the middle segment blade, interpolation fitting is performed between the middle segment and the rear cone blade.

The interpolation operation is based on the Eq. (6) and the Eq. (8). In order to ensure the mixing and the discharging performance between the middle segment blade and the rear cone blade, there are $n$ points selected from the $i$ equal points to interpolate a fitting blade.

In addition, the degree change of blade inclination is

$$
p=\frac{u}{n}=\frac{w}{n},
$$

where, $u$ is the blade inclination angle, $n$ is the interpolation point.

Change of interpolation of horizontal coordinate is

$\Delta R_{n}=B \cdot \cos [u-n \cdot p]$

where, $B$ is the blade width, $u$ is the inclination angle of the middle section blade, $n$ is the interpolation point.

Change of interpolation of vertical coordinate is

$\Delta Z_{n}=B \cdot \sin [u-n \cdot p]$

where, $B$ is the blade width, $u$ is the inclination angle of the middle section blade, $n$ is the interpolation point.

The adjoint equation of the root of spiral interpolation blade is

$$
\left\{\begin{array}{l}
r=M R_{1}(i) \\
\text { theta }=\varphi(i) \\
z=M_{z n}(i)
\end{array}\right.
$$

where, $M R_{1}(i)$ is the root horizontal coordinate of the interpolation point; $\varphi(i)$ is the angle of the interpolation point; $M_{z n}(i)$ is the root vertical coordinate of the interpolation point.

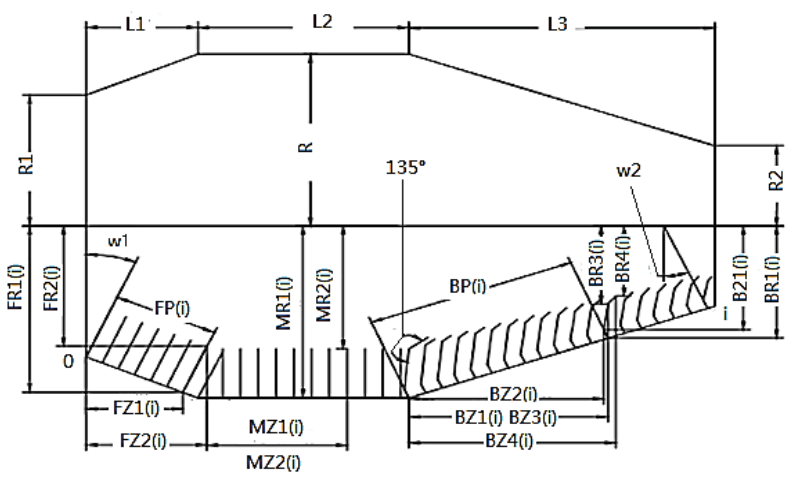

Figure 7 The design dimensions of mixing tank (enlarge this picture)

The adjoint equation of the top of spiral interpolation blade is

$$
\left\{\begin{array}{l}
r=M R_{1}(i)-\Delta R_{n}(i) \\
\text { theta }=\varphi(i) \\
z=M_{z n}(i)+\Delta Z_{n}(i)
\end{array},\right.
$$

where, $M R_{1}(i)$ is horizontal coordinate of the root of $i$ interpolation point; $\varphi(i)$ is the angle of the interpolation point; $M_{z n}(i)$ is the root vertical coordinate of the interpolation point; $\Delta R_{n}(i)$ is the horizontal coordinate change of the interpolation point; $\Delta Z_{n}(i)$ is the change in $z$ direction vertical coordinate of the interpolation point.

\subsection{Three-Dimensional Fitting of the Interpolated Blade}

The three-dimensional design is proposed by the piecewise process based on curves and surfaces of blade. In Pro/E5.0 code $\AA$, using the results of calculation of the 2.2 to do "insert - curve - the adjoint equation - cylindrical coordinate- input ( $r$, theta and $z$ ) - spiral forming - mixed sweep", the transitional spiral blade is formed as shown in Fig. 8 .

The blade which is fitted perfectly in the mixing tank is very important in the design of blade. As shown in Fig. 9, we use the MFG to solve the problem of the connection of spiral blades basically. The assembly of the blades and tank is very good, as shown in Fig. 10. Seen from Fig. 9 and Fig. 10, the blade designed in this way has good fitting property. It needs not to modify the related parameters of blade frequently, such as spiral angles, fitting parameters of blade's width. So we can improve the efficiency greatly when designing the connection of spiral blade of concrete mixing tank. The MFG solves the connecting problem in the process of blade design. 


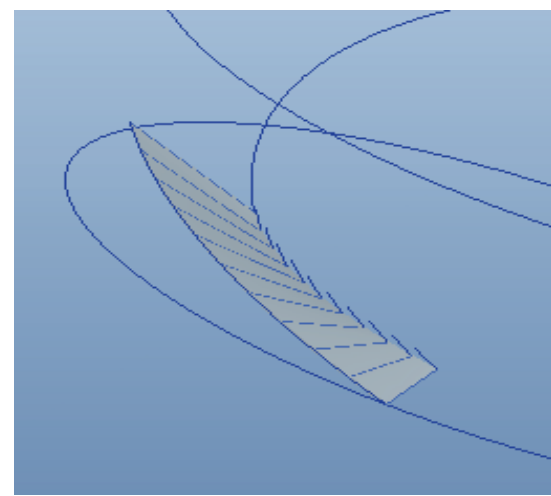

Figure 8 The transitional fitting of the blade

\section{ACTUAL PRODUCTION AND PROCESS-VALIDATION}

According to Fig. 8, we can get the three-dimensional forming figure of interpolation fitting blade, as shown in Fig. 9. And then the blade can be formed by the punching press or the Advanced Mold Manufacturing Technology [20-23]. In blanking the thin material of blade, the planetriangle principle [24] can be used to calculate the area of raw thin steel plate. So, the spiral blade can be expanded into a plane, as shown in Fig. 11. The blank of blade is processed by using the Electric Discharge Wire-cutting Technology. Finally, the installation effect of the blade in mixing tank is shown in Fig. 12 and Fig. 13. It can be seen from Fig. 12 that fitting blade has good fitting effect verifying the feasibility of the MFG. In Fig. 13, we also can see that fitting blade has good welding property. The welds are well-proportioned, and the junction of blade does not need hammer to correct. The fitting blade designed by the MFG is smoother than traditional connecting blade, having longer service life during the actual application. Therefore, the application of the MFG has a practical significance for improving the performance of the stirring tank.

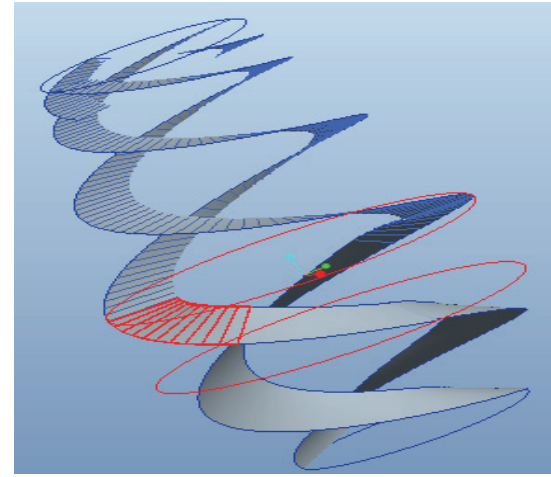

Figure 9 The 3D assembly of fitting spiral blade

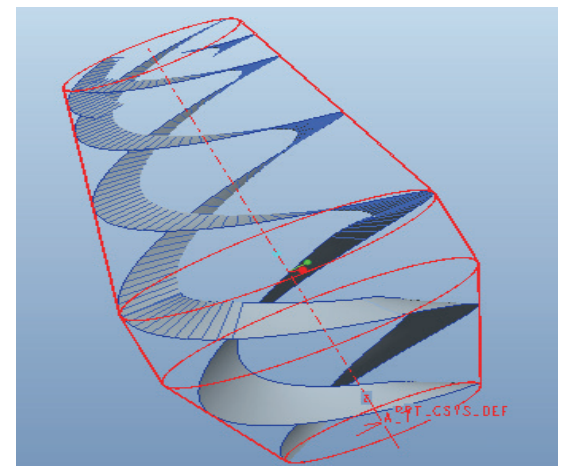

Figure 10 The 3D assembly of spiral blade and mixing tank

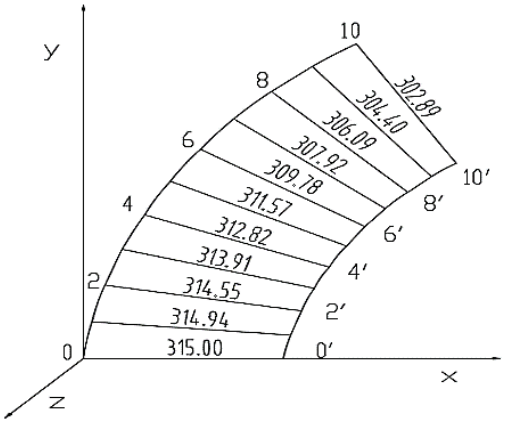

Figure 11 The unfolded plane geometry of the curved surface of spiral blade

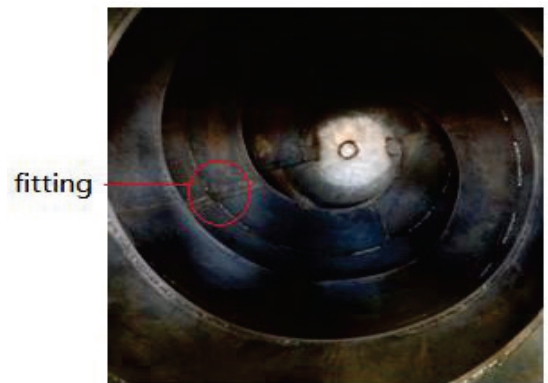

Figure 12 The installation of conical logarithmic spiral blades

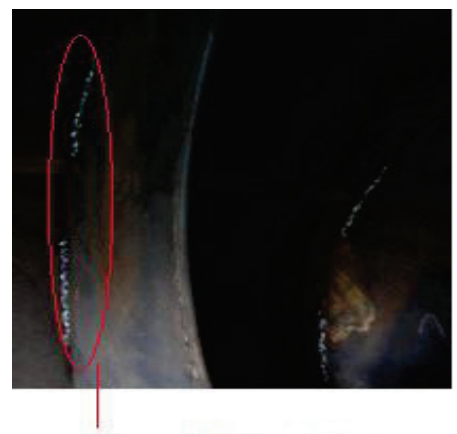

welding of fitting blade

Figure 13 The actual welding installation of the fitting blade

\section{THE EXPERIMENTS OF STIRRING AND DISCHARGING PERFORMANCE}

The test conditions of mixing and discharging performance for concrete mixing tank are as follows: the material of mixing is crushed sand; the effective capacity of the mixing tank is $3 \mathrm{~m}^{3}$; the feeding speed is not less than $1.5 \mathrm{~m}^{3} / \mathrm{min}$; the discharging speed of mixing tank is $2-3$ $\mathrm{m}^{3} / \mathrm{min}$; the rotating speed of tank is $18 \mathrm{rpm}$ under mixing condition; the rotating speed of tank is $-12 \mathrm{rpm}$ under discharging condition. The installation of weighing sensor system is under the mixing tank shown in Fig. 14.

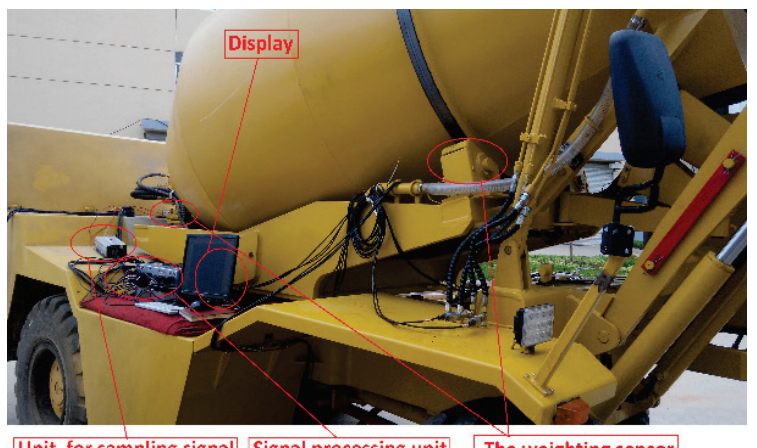

Unit for sampling signal Signal processing unit The weighting sensor Figure14 The installation of weighing Sensor System 
After the installation and completed debugging, the test system is shown in Fig. 15. In the process of sensor calibration, the weighing system is zero when the load is empty.

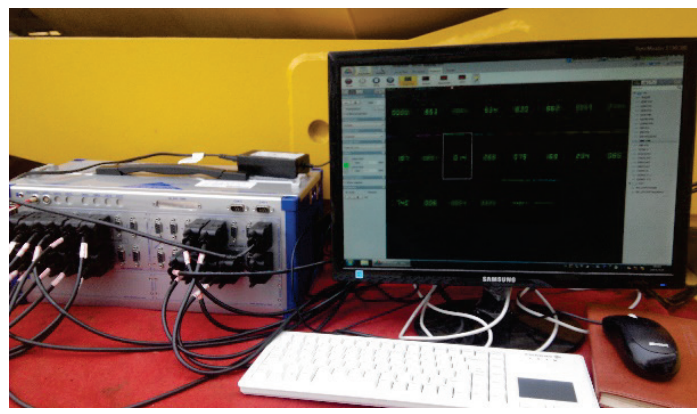

Figure 15 The debugging of weighing system
The weighing system has a testing range of $0-8000 \mathrm{~kg}$. Then we carry on experiments, the process of load and unload is shown in Fig. 16.

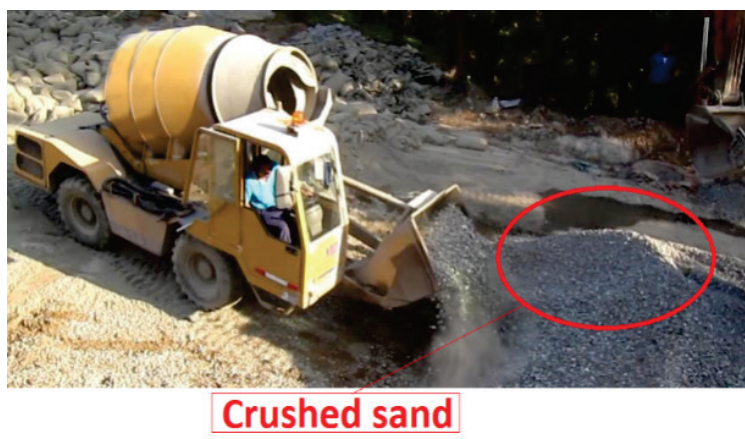

Figure 16 The loading and unloading work of mixing tank

Table 1 The related test results

\begin{tabular}{|c|c|c|c|c|c|}
\hline Test & Feeding time / s & full-load weight / kg & Discharging time / s & Residual weight / kg & Discharging residual rate / \% \\
\hline 1 & 66 & 7198.5 & 89 & 20.5 & 0.285 \\
\hline 2 & 73 & 7188.4 & 87 & 14.7 & 0.204 \\
\hline 3 & 69 & 7201.3 & 82 & 21.3 & 0.296 \\
\hline
\end{tabular}

Three non-sequential measurement repetitions are made in identical conditions. The tank is fully loaded in every test condition, and the mixture material is starting to discharge after stirring for 5 minutes. The test results are shown in Tab. 1. The discharge performance is expressed by the Discharging residual rate, Discharge residual rate = (Residual weight)/(full-load weight) $\times 100 \%$. Where, Residual weight $=($ full-load weight $)-($ discharge weight $)$. And the weight result of three tests under the weighing system is shown in Fig. 17, Fig. 18 and Fig. 19 respectively.

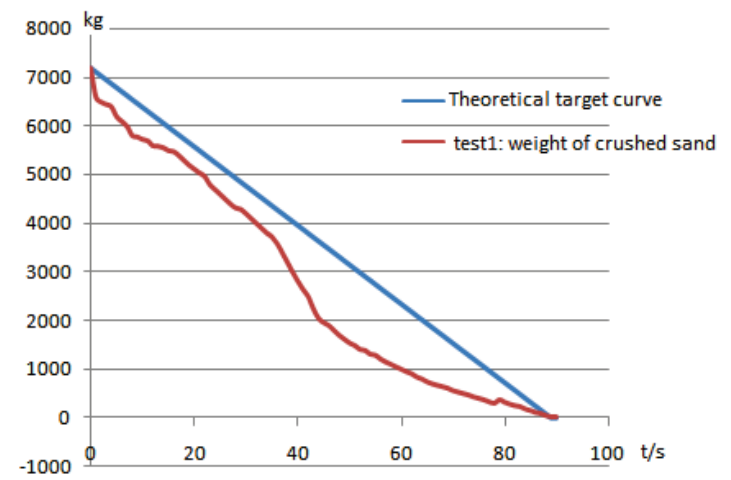

Figure 17 The dynamic discharging display of weighing system in test 1

As seen in Tab. 1, the average feeding speed of three tests is $2.686 \mathrm{~m}^{3} / \mathrm{min}, 2.46 \mathrm{~m}^{3} / \mathrm{min}$ and $2.61 \mathrm{~m}^{3} / \mathrm{min}$ respectively, meeting the relevant test standards of industry. These indicate that the feeding performance is satisfied basically.

The average discharging speed of three tests is 2.01 $\mathrm{m}^{3} / \mathrm{min}, 2.06 \mathrm{~m}^{3} / \mathrm{min}$ and $2.2 \mathrm{~m}^{3} / \mathrm{min}$ respectively, meeting the relevant test standards of industry. These indicate that the discharging performance is great. From Fig. 17 to Fig.19, the actual discharging speed is slow at first, then fast and slow at last. The reason for this situation is that the time response of the mixing tank is delayed at the beginning, but later it becomes a normal discharge. With the material decreasing, the discharging thrusting decreases, so the discharging speed decreases finally. In an entire process of discharging, the speed fluctuation is small, and the discharging speed is highly stable. The discharging residual rate of three trials is $0.285 \%, 0.204 \%$ and $0.296 \%$ respectively, which is better than other mixing tank in market. Therefore, the stirring tank designed by the MFG obtains good stirring and discharging performance.

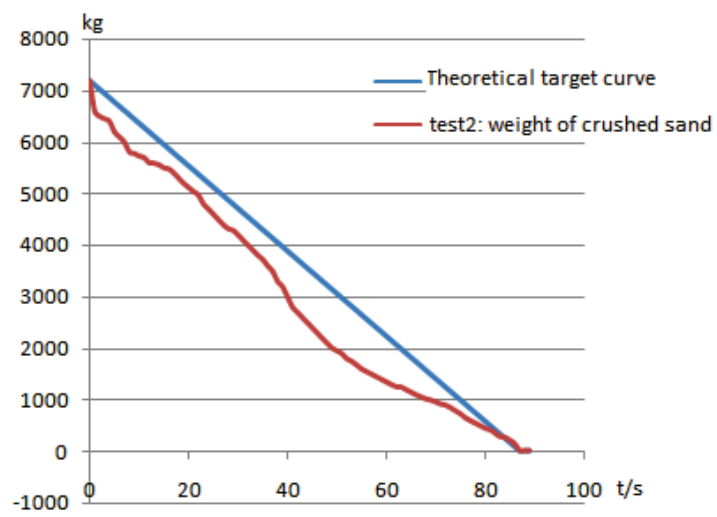

Figure 18 The dynamic discharging display of weighing system in test 2

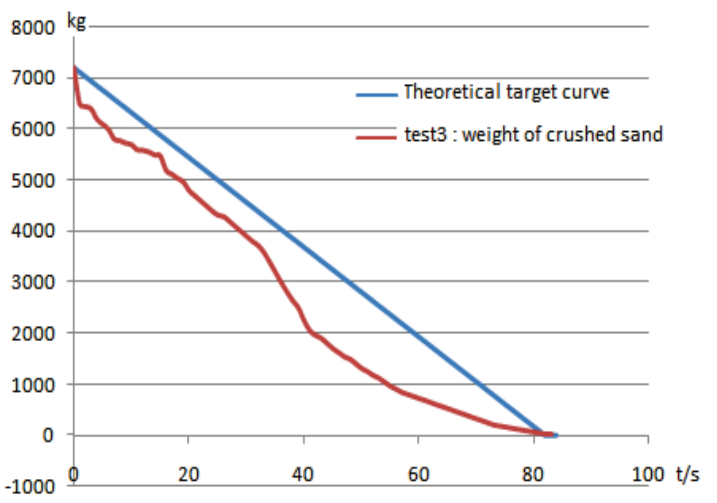

Figure 19 The dynamic discharging display of weighing system in test 3

\section{THE SIMULATION OF MULTI-PHYSICS FIELD COUPLING}

\subsection{Multi-field Coupling Simulation and Parameters}

In the working process, the concrete mixing tank is affected by the coupling of mixed fields, including 
gravitational field, pressure field, motion field, density field, flow field, solid field and gas field. The internal concrete state of the mixing tank is very complex. The mixing tank is affected by complex forces, such as tension, pressure, bending, torsion, etc. So it is difficult to test the actual applied force in mixing tank. In this paper, the coupling state of concrete and agitator is studied by means of visual coupling simulation. Based on 17 - STARCCM + code $\AA$, we carry on the coupling simulation to study the internal motion state of concrete, the force state of the stirring tank and the function for each segment of blades visually. The research provides a powerful reference for the design of the conical logarithmic concrete mixing tank in the future.

The setting of the gravity field matrix is $\left[0,-\mathrm{g} \cdot \sin 75^{\circ}\right.$, $\left.-\mathrm{g} \cdot \sin 15^{\circ}\right]$. Considering the osmotic effect of solid, liquid and gas, the initial pressure of mixing tank is set to $3 \mathrm{MPa}$ [25-32]. The parameter of the motion field is set to +18 $\mathrm{r} / \mathrm{min}$ (mixing condition), $+3 \mathrm{r} / \mathrm{min}$ (transporting condition), $-12 \mathrm{r} / \mathrm{min}$ (discharging condition) respectively, which is applied to dynamic grid movement area in every condition. Considering actual situation and three phase coupling consisting of solid, liquid, gas, we adopt the Multi-Phase Euler Model. Meanwhile, we set cement and sand to discrete solid particles, and set water and air to the continuous phase. The interaction between different phases is determined and the turbulent loading model is established. In addition, the density of sand, water and air is set to $1500 \mathrm{~kg} / \mathrm{m}^{3}, 1000 \mathrm{~kg} / \mathrm{m}^{3}, 1.16 \mathrm{~kg} / \mathrm{m}^{3}$ respectively.

\subsection{The Results of the Coupling Simulation 5.2.1 Simulation Results of Concrete Flow State}

The simulation results show that the streamline state of single particle of the concrete in the mixing tank, as shown in Fig. 20, is 60 seconds after the start of each working condition and 60 seconds before the end of each working condition. The motion state of concrete solid particle in the coupling state of Multi-Physics Field is analyzed in detail when feeding, mixing, transporting and discharging. The visual motion results are served as the verification standard of the internal state of the mixing tank. Fig. 20a and Fig. $20 \mathrm{~b}$ show the moving streamline of concrete solid particle under the feeding condition. Fig. 20c and Fig. 20d show the moving streamline of the concrete solid particle under the stirring condition. Fig. 20e and Fig. 20f show the moving streamline of concrete solid particle under the transporting condition. Fig. $20 \mathrm{~g}$ and Fig. $20 \mathrm{~h}$ show the moving streamline of the concrete solid particle under the discharging condition.

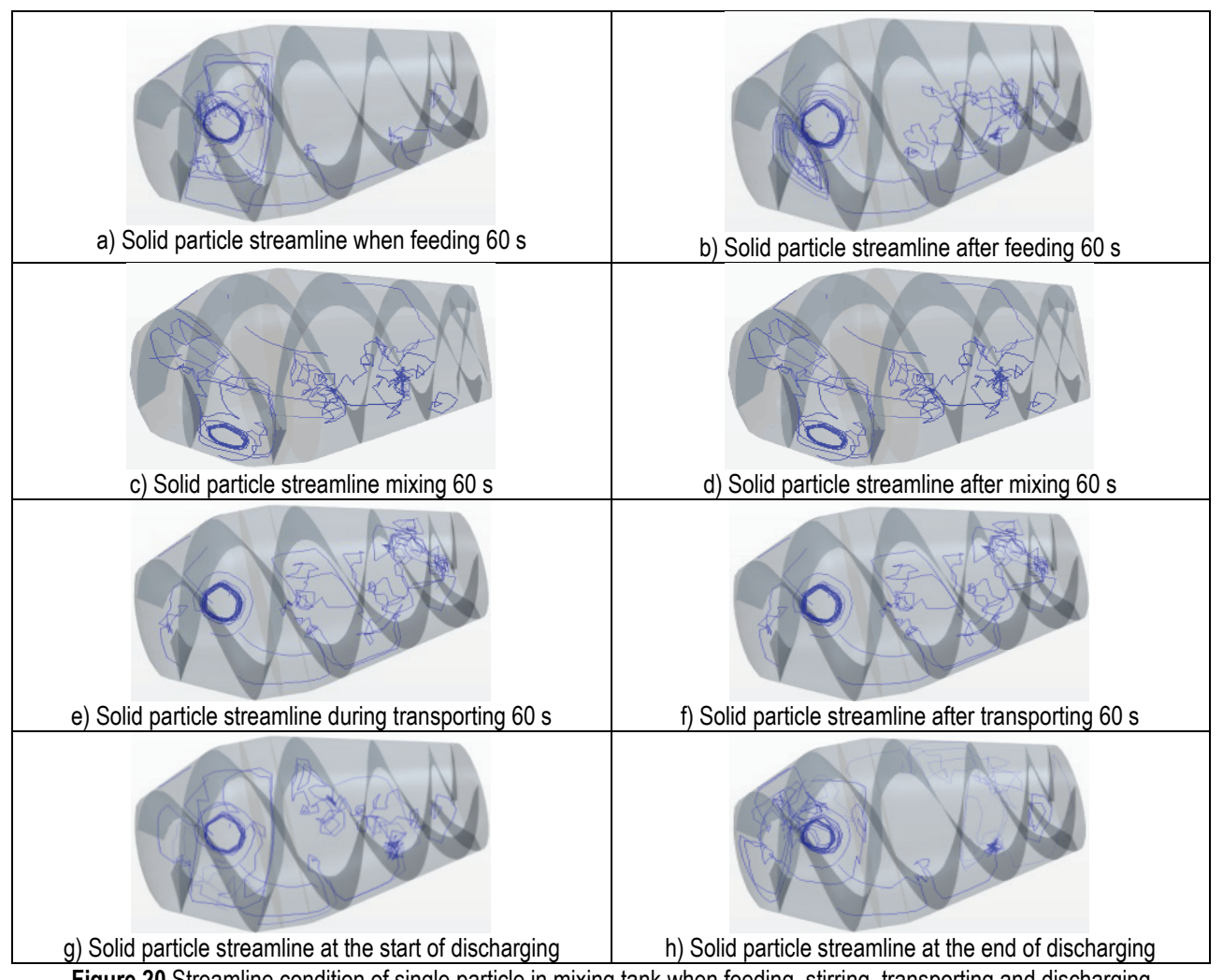

The distribution of solid particle shows the mixing performance of the mixing tank. The more cluttered streamline is, the better mixing performance is. From Fig. 20a to Fig. 20f, we can see that the streamline distribution of solid particle in the concrete mixing tank is very chaotic when the tank is mixing, indicating that the mixing rate of the mixing tank is very good. From Fig. 20g and Fig. 20h, we can also see the dynamic flow of solid particle in the tank during the unloading process, indicating that the discharging rate of the mixing tank is great as well.

\subsubsection{Simulation Verification of Stirring Performance}

In $17-S T A R C C M+\operatorname{code} \AA$, we use scalar scenes to show the mixing performance. To say, the volume fraction distribution of solid particles is used to characterize the agitation performance at the first 60 seconds when stirring and transporting (initial value: the volume fraction of sand and cement is 0.6 , water 0.3 , air 0.1 ).

As shown in Fig. 21a and Fig. 21b, the volume fraction distribution of solid particle is very close to 0.6 . The 
stirring rate of concrete mixing tank is over $95 \%$. Fig. $21 \mathrm{c}$ and Fig. 21d show that the mixing evenness rate of concrete can reach $100 \%$ from the end of mixing to the beginning of unloading. These indicate that the mixing tank has good stirring performance.

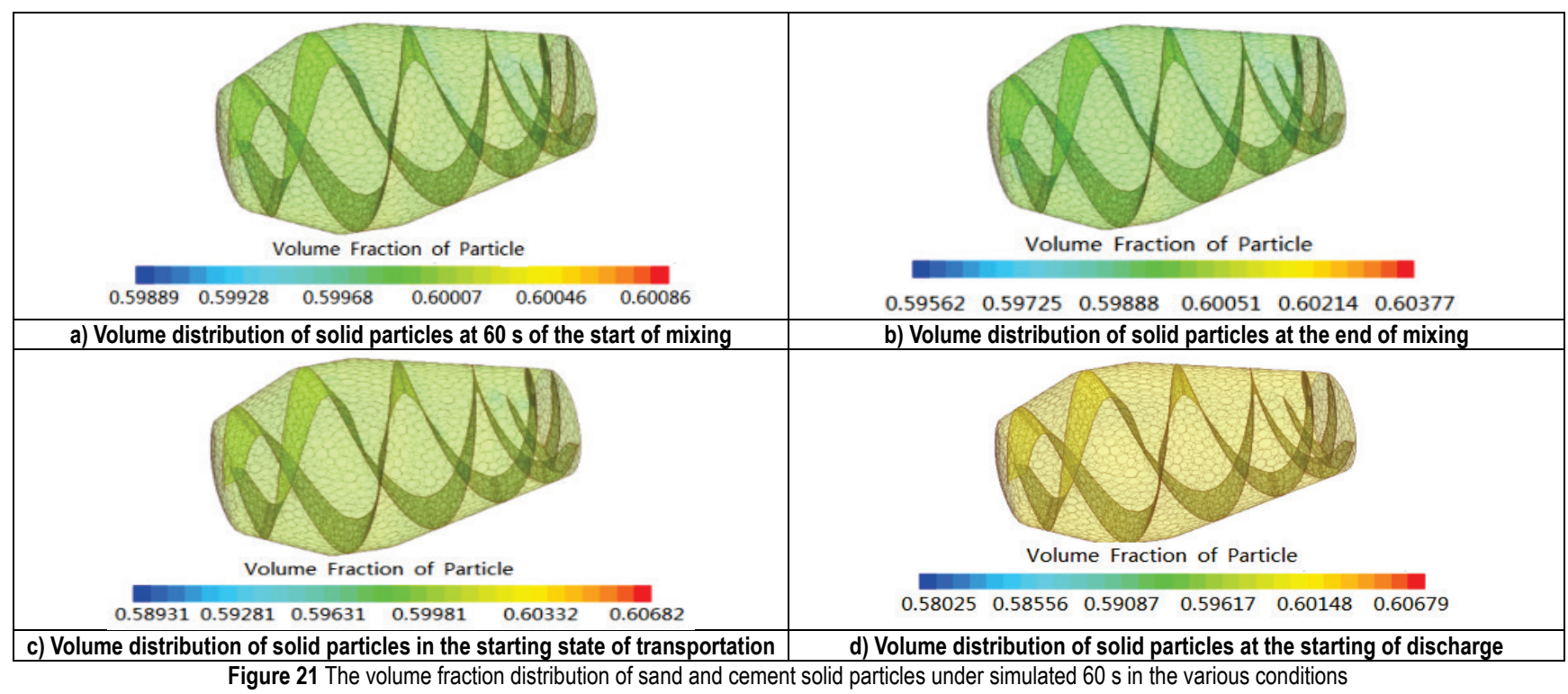

\subsubsection{The Stress Situation at Various Working Times}

In the $17-S T A R C C M+\operatorname{code} \AA$, the vector scenes are used to display the applied force state and the dangerous point of the stirring tank in the rotating process. The

simulation time is 60 seconds in various working conditions, and the stress nephogram of every working condition is shown in Fig. 22. The unit of wall shears stress in nephogram is msi.

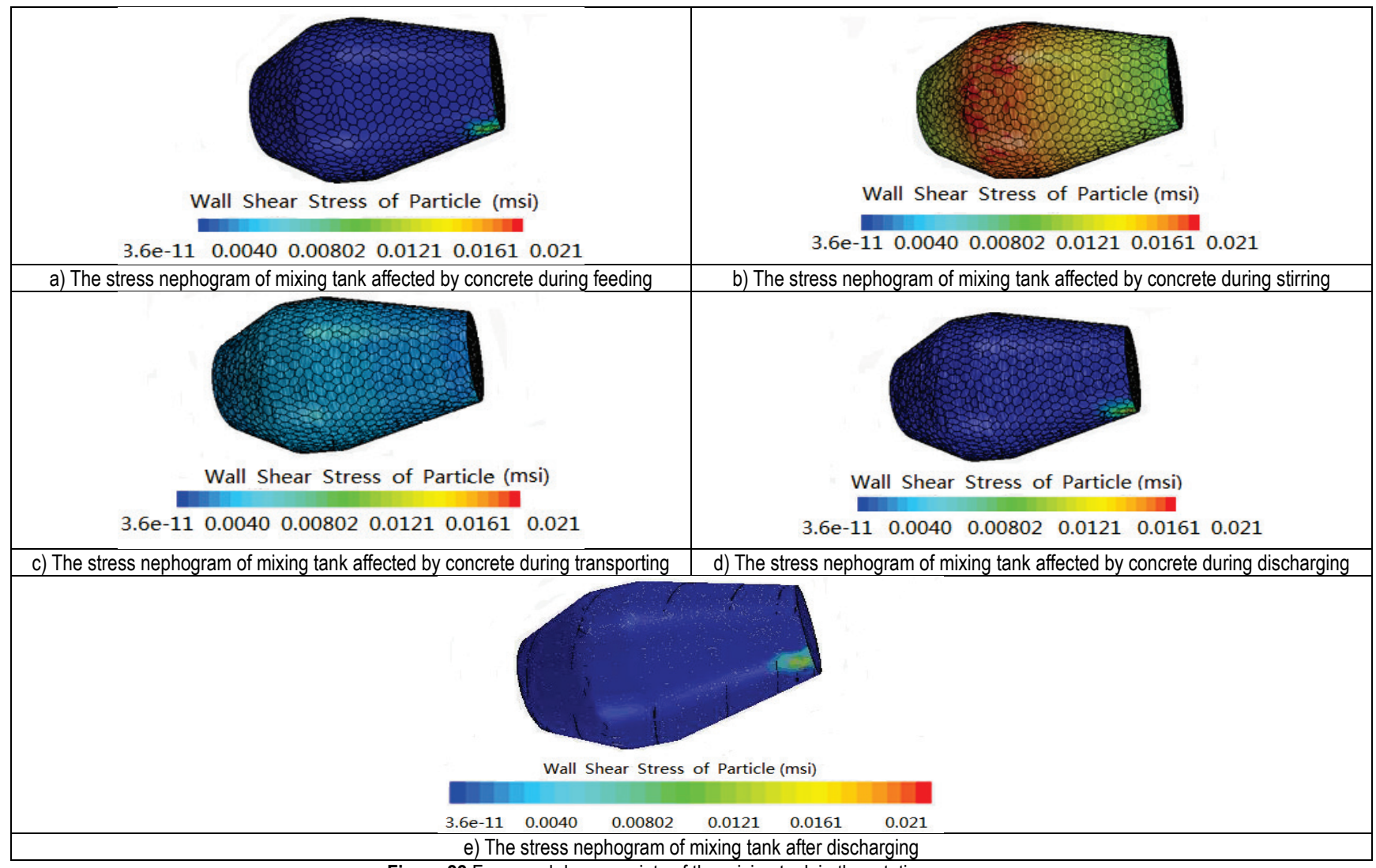

Figure 22 Force and danger points of the mixing tank in the rotating process

Fig. 22a shows that the dangerous point is at the mouth of the mixing tank when feeding. Fig. 22b shows that the most severe worn parts of the mixer are located in the anterior cone and the front part of the middle segment when stirring. As shown in Fig. 22c, due to the decrease of rotating speed, the material has been stirred equally and the wear and abrasion of tank's wall have been reduced during transporting. As shown in Fig. 22d, the main wear part of 
the tank's wall is at the mouth of the tank at the beginning of unloading. As shown in Fig. 22e, the wear and abrasion of tank's wall at the end of unloading is more serious than that at the beginning of unloading.

Fig. 22 shows that the design about mixing tank and blade is reasonable. And the dangerous point and easy wear point are at the mouth of the tank. As for the design of stirring tank, we can enhance the intensity of blade and increase service life of mixing tank by edging protection of blade.

\section{CONCLUSIONS}

(1) We provide an up-to-date reference for the design of the gap connection of the conical logarithmic spiral blade. We solve the previous connection problem of spiral blade perfectly. And the MFG ameliorates the performance of the mixing and discharging and enhances the service life of the blade.

(2) The MFG for blade is verified through related test and actual production. It has a good effect on the connection of conical logarithmic spiral blade.

(3) Two important performances of concrete mixing tank are verified experimentally. The experimental results show that the connecting blade designed by the MFG has good connecting, mixing and discharging performance.

(4) Under complex stress conditions, the coupling simulation of Multi-Physics Field is used to visualize the performance of concrete mixing tank in various conditions. Finally, the mixing and discharging of the tank designed by the MFG are verified. And, the dangerous parts of concrete mixing tank in various working conditions are displayed visually, which provides a reference for the rational design of concrete mixing tank.

\section{Acknowledgment}

The work was supported by National Natural Science Foundation of China (Grant No. 51405187).

\section{REFERENCES}

[1] Tsui, Y. Y. \& Hu, Y. C. (2011). Flow characteristics in mixers agitated by helical ribbon blade impeller. Engineering Applications of Computational Fluid Mechanics, 5(3), 416429. https://doi.org/10.1080/19942060.2011.11015383

[2] Gan, C. Y., Sahari, K. S. M., \& Tan, C. S. (2015). Numerical investigation on Coanda flow over a logarithmic surface. Journal of Mechanical Science \& Technology, 29(7), 28632869. https://doi.org/10.1007/s12206-015-0615-y

[3] Yang, J. M. (1984). Design of spiral blade for mixing drum of concrete mixer truck. Construction Machinery, (2), 8-15.

[4] Zhang, J., Guo, Z., Li, R., Wang, W., Zhang, A., Liu, J. et al. (2015). Circular polarization analyzer based on the combined coaxial Archimedes' spiral structure. Plasmonics, 10(6), 1255-1261. https://doi.org/10.1007/s11468-015-9917-2

[5] Lai, B. \& Chen, Y. T. (2009). PRO/E three dimensional design of spiral blade on concrete mixer truck mixing drum. Construction Machinery, 12(24), 94-96.

[6] Bin, L. I., Wang, K., \& Anna, K. E. (2015). The Parametric Design Method for Helical Blades of Concrete Mixer Truck. Journal of Shenyang Jianzhu University, 31(2), 335-343.

[7] Rahimi, M. \& Parvareh, A. (2005). Experimental and CFD investigation on mixing by a jet in a semi-industrial stirred tank. Chemical Engineering Journal, 115(12), 85-92. https://doi.org/10.1016/..cej.2005.09.021

[8] Shi, L., Zhou, S. J., Yang, F. L., \& Hu, F. J. (2011). Numerical simulation of turbulent mixing for dislocated blades in a stirred tank. Advanced Materials Research, 354(355), 559563. https://doi.org/10.4028/www.scientific.net/AMR.354-355.559

[9] Tamburini, A., Cipollina, A., Micale, G., Brucato, A., \& Ciofalo, M. (2011). Cfd simulations of dense solid-liquid suspensions in baffled stirred tanks: prediction of suspension curves. The Chemical Engineering Journal, 178(1), 324-341. https://doi.org/10.1016/j.cej.2011.10.016

[10] Guha, D., Ramachandran, P. A., Dudukovic, M. P., \& Derksen, J. J. (2010). Evaluation of large eddy simulation and euler-eulercfd models for solids flow dynamics in a stirred tank reactor. Aiche Journal, 54(3), 766-778. https://doi.org/10.1002/aic.11417

[11] Lee, K. C. (1995). An experimental investigation of the trailing vortex structure and mixing characteristics of stirred vessels. Open grey repository, 1, 766-778, University of London.

[12] Ranade, V. V. \& Deshpande, V. R. (1999). Gas-liquid flow in stirred reactors: trailing vortices and gas accumulation behind impeller blades. Chemical Engineering Science, 54(13). https://doi.org/10.1016/S0009-2509(98)00301-7

[13] Deglon, D. A. \& Meyer, C. J. (2006). Cfd modelling of stirred tanks: numerical considerations. Minerals Engineering, 19(10), 1059-1068. https://doi.org/10.1016/j.mineng.2006.04.001

[14] Zadghaffari, R., Moghaddas, J. S., \& Revstedt, J. (2009). A mixing study in a double-rushton stirred tank. Computers \& Chemical Engineering, 33(7), 1240-1246. https://doi.org/10.1016/j.compchemeng.2009.01.017

[15] Liu, X., Bao, Y., Zhipeng, L. I. et al. (2008). Particle Image Velocimetry study of turbulence characteristics in a vessel agitated by a dual rushton impeller. Chinese Journal of Chemical Engineering, 16(5), 700-708. https://doi.org/10.1016/S1004-9541(08)60143-3

[16] Ferraris, C. F. (2001). Concrete mixing methods and concrete mixers: state of the art. Journal of Research of the National Institute of Standards \& Technology, 106(2), 391-399. https://doi.org/10.6028/jres.106.016

[17] Fedorko, G., et al. (2015). Determination of Calculation for the Shape of Blades Trace in the Concrete Mixer Truck. Procedia Technology, 19, 395-401. https://doi.org/10.1016/j.protcy.2015.02.056

[18] Gao, Y. D., Ma, Y. Z., \& Kong, X. G. (2013). Analysis and Optimization on the Front Supporter of Concrete Mixer Truck. Applied Mechanics \& Materials, 385(386), 288-291. https://doi.org/10.4028/www.scientific.net/AMM.385-386.288

[19] Chen, Y. L. et al. (2011). Design of Digital Display Control Devise System for Concrete Mixer Truck. Applied Mechanics \& Materials, 55(57), 63-67. https://doi.org/10.4028/www.scientific.net/AMM.55-57.63

[20] Xu, J. P., Fang, J. C., \& Li, Z. G. (2002). Plasma jet imaging by CCD technology in rapid mold manufacturing. Journal of Materials Processing Technology, 129(13), 250-254. https://doi.org/10.1016/S0924-0136(02)00612-X

[21] Wang, M. Y. \& Chen, S. (2009). Compliant mechanism optimization: analysis and design with intrinsic characteristic stiffness. Mechanics Based Design of Structures and Machines, 37(2), 183-200. https://doi.org/10.1080/15397730902761932

[22] Serizawa, M. \& Matsumura, T. (2016). Control of helical blade machining in whirling. Procedia Manufacturing, 5, 417-426. https://doi.org/10.1016/j.promfg.2016.08.035

[23] Wang, J. H. et al. (2005). Numerical simulation for sheet metal forming process of $16 \mathrm{Mn}$ blade of large concretemixer truck. Journal of Central South University, 12(1), 8387. https://doi.org/10.1007/s11771-005-0209-4

[24] Zeng, X. Z., Chen, Y. T., \& Mao, Y. (1991). Expansion calculation of spiral blade for mixing drum of concrete mixer 
truck. Construction Machinery and Equipment, 10(12), 1752.

[25] Grilli, S. T., Skourup, J., \& Svendsen, I. A. (1989). An efficient boundary element method for nonlinear water waves. Engineering Analysis with Boundary Elements, 6(2), 97-107. https://doi.org/10.1016/0955-7997(89)90005-2

[26] Oesterle, B. \& Petitjean, A. (1993). Simulation of particleto-particle interactions in gas solid flows. International Journal of Multiphase Flow, 19(1), 199-211. https://doi.org/10.1016/0301-9322(93)90033-Q

[27] Jaime, M. J., Cazacliu, B., Cothenet, A., Artoni, R., \& Roquet, N. (2016). Recycled concrete aggregate attrition during mixing new concrete. Construction \& Building Materials, 116, 299-309.

https://doi.org/10.1016/j.conbuildmat.2016.04.131

[28] Hanna, K. M. \& El-Hemaly, S. A. (2010). Effect of curing conditions on the total water content of hardened portland cement paste. Journal of Chemical Technology \& Biotechnology, 19(9), 241-244. https://doi.org/10.1002/jctb.5010190901

[29] Bouremel, Y., Yianneskis, M., \& Ducci, A. (2009). Threedimensional deformation dynamics of trailing vortex structures in a stirred vessel. Industrial \& Engineering Chemistry Research, 48(17), 8148-8158. https://doi.org/10.1021/ie801481v

[30] Demirhan, N. \& Kanber, B. (2008). Stress and displacement distributions on cylindrical roller bearing rings using fem. Mechanics Based Design of Structures and Machines, 36(1), 86-102. https://doi.org/10.1080/15397730701842537

[31] Banichuk, N., Kurki, M., Neittaanmäki, P., Saksa, T., Tirronen, M., \&T uovinen, T. (2013). Optimization and analysis of processes with moving materials subjected to fatigue fracture and instability. Mechanics Based Design of Structures \& Machines, 41(2), 146-167. https://doi.org/10.1080/15397734.2012.708630

[32] Salgado, R. \& Prezzi, M. (2007). Computation of Cavity Expansion Pressure and Penetration Resistance in Sands. International Journal of Geomechanics, 7(4), 251-265. https://doi.org/10.1061/(ASCE)1532-3641(2007)7:4(251)

\section{Contact information}

\section{Xinhui LIU}

School of Mechanical and Aerospace Engineering,

Jilin University, Changchun, 130025, China

\section{Yanhong SONG}

School of Mechanical and Aerospace Engineering,

Jilin University, Changchun, 130025, China

School of Engineering,

Changchun Normal University, Changchun, 130031, China

\section{Feng REN}

(Corresponding author)

School of Mechanical and Aerospace Engineering,

Jilin University, Changchun, 130025, China

School of Engineering,

Changchun Normal University, Changchun, 130031, China

E-mail: renfeng_jlu@163.com

\section{Jinshi CHEN}

School of Mechanical and Aerospace Engineering,

Jilin University, Changchun, 130025, China

\section{Min ZHAO}

Jilin University, Changchun, 130025, China 